\title{
Analysis on the Operational Effect of Management Mode of Financial Shared Service Center of Large and Medium-sized Enterprises in China
}

\author{
Honggang Tian
}

The Seventh Metallurgical Construction Corp.Ltd, Guizhou, Guiyang, 550061

Keywords: large and medium-sized enterprises; financial management; financial shared service center; operational effects; countermeasures

\begin{abstract}
With the rapid development of economic globalization and modern network technology, the competitive pressure between enterprises has become more intense. In China's large and medium-sized enterprises, the application of the management mode of financial shared service centers has been promoted. This is the financial management of modern large and medium-sized enterprises in China. Running the financial sharing service center management can effectively reduce the economic cost and human resources of the enterprise, and quickly do a good job in fund management and financial decision-making with the help of modern technology, improve the efficiency of the financial management, obtain the maximum economic profit and at the same time strive for more perseverance for the enterprise. However, there are operational problems in the management mode of financial shared service centers in large and medium-sized enterprises in China. In the context of the widespread industry, there are still deficiencies that need to be improved. This paper focuses on the operational difficulties of the financial shared service center management model, analyzes the object and makes suggestions for improvement.
\end{abstract}

\section{Introduction}

Since the 21st century, the management concept of financial sharing services has been introduced to China from the United States. In the context of the continuous improvement of China's construction level, it has also provided a better space for financial sharing services. China's large and medium-sized enterprises have gradually developed into a group-scale scale. The traditional financial management system is too fragmented to meet the huge fund amount statistics and financial related work management of large and medium-sized enterprises today, in financial accounting, material procurement, contract signing, etc. Too much consumption of the company's operating costs, so running a financial shared negative debt center management model is a necessary and feasible management model. In this paper, the status quo of the management of financial sharing service centers in large and medium-sized enterprises is proposed. The financial information sharing mechanism is improved, the financial materials are shared, the professional management of financial management personnel is improved, the financial and production sharing system is optimized, and the best development is made. Six aspects of enterprise strategic planning and control of investment risk propose operational countermeasures.

\section{The Role of Financial Sharing Service Center Management Model in Improving Financial Management Level}

In order to be able to pursue greater operating profit, China's large and medium-sized enterprises have increased the opening of branch offices. Although they have seized the production competitiveness of various regions and improved the production scale of enterprises as a whole, they have shown in financial management and production management. The disadvantages of scattered and lack of unity in various regions, the decentralized management of regional companies has increased the operating costs of human resources, adding to the difficulty of the overall management and decision-making of enterprises, and overall lowering the implementation efficiency of the development strategy of enterprises. Under the management mode of the financial 
shared service center, through the service center to uniformly handle the accounting work of each subsidiary's financial business, tax reporting, monthly accounting, etc., it can save a lot of financial staff's rework time, and can give the company high quality, Efficient financial data information support, more comprehensive monitoring of data on various production and operation activities of enterprises, helping enterprises to better develop strategic plans.

The financial positions of large and medium-sized enterprises in China are mainly configured according to their actual needs. Due to the large number of branches, the expansion of production scale, and the differences between branches, the financial management of enterprises becomes complicated and cumbersome. The audit to the corporate headquarters has many procedures and long time, which has lowered the financial management efficiency of the enterprise and affected the production and operation of the entire enterprise. With the help of the financial sharing service center, the company's financial information can be received in a timely manner, and the financial staff of the headquarters can manage it on the shared service platform, saving financial repetitive work costs and achieving efficient collection, high-speed delivery, accurate analysis and perfect processing. Integrate financial sharing management to improve the overall management and control of corporate finance.

The management mode of the large and medium-sized enterprises running the financial sharing service center can simplify the business data and production information by using the modern Internet platform without changing the business process and the production mode of the enterprise, and eliminate the labor costs of repeated finishing operations. The financial information of the production areas and branch offices, the standardization of information resources, and the standardized management, one person can dock the financial affairs of many subsidiaries and reduce the operating labor costs of the enterprises.

The operation mode of the financial sharing service center has realized the highly centralized management of all departments of large and medium-sized enterprises, such as production business, procurement and sales, human resources, logistics and logistics, and can monitor various operational data in real time, providing branches and internals in the first time. The work evaluation of the department has improved the work efficiency and management service quality. The open and standardized sharing management has strengthened the staff's work attitude and responsibility awareness, thus reducing the internal audit risk and tax risk.

\section{The Problems in Operation Process of Financial Sharing Service Center Management Mode}

Under the convenient management of the financial sharing service center, the financial personnel no longer need to face the financial personnel of the branch and various departments, and it is not related to other businesses such as personnel and performance review. Only financial consolidation and funds are completed on the sharing center. Control and other accounting work, more biased towards the general agent's working relationship, reducing interpersonal communication will result in a weak sense of service for financial personnel, but also focus on "sharing" and neglecting "services". The existence of financial shared service centers is for the entire enterprise to More efficient and accurate operation, while achieving centralized and real-time management, we must also pay attention to the financial staff's work attitude and service spirit.

Tax management is concentrated on the service platform after running the financial shared service center. Direct communication with the local tax bureau is blocked. There is backwardness in receiving instant news such as local tax incentives, tax rebates and tax rate changes, and it is easy to miss a large number. At the same time, the management mode of the financial sharing service center also has computer hardware damage and network platform viruses and vicious attacks. Once it is damaged, it will permanently lose important information of the enterprise and greatly hinder the development of the enterprise. At this point, financial management personnel must do a good job of security protection.

The decentralized financial management system is the basic management mode of large and medium-sized enterprises for a long time. Once transformed into a financial shared service center, it 
is equivalent to cross-level accounting, which is not only the transformation of the financial personnel team, but also the transformation of the internal management structure of the enterprise. After adjusting to the shared service center, the financial personnel will have a clearer separation of accounting duties and management responsibilities, which is equivalent to an overall change of the financial department. Secondly, the financial department as the core management of the enterprise, once the management model is changed, the organizational structure of the entire enterprise is also Need to cooperate with the substantial adjustment, will be affected by the traditional management model concept and personnel transformation resistance.

\section{Strengthen the Improvement of Management Mode of Financial Sharing Service Center in Large and Medium-sized Enterprises}

Large and medium-sized enterprises can control the operation of each fund by running a financial sharing platform, centrally manage cash and bank transactions, and reduce the liquidity collection and payment activities to enhance the stability of corporate capital. Improve internal financial information management and control of financial activities through shared service centers and direct bank monitoring. In addition, the Financial Shared Service Center can further standardize the information sharing mechanism of corporate finance, and can combine financial information analysis, cost capital budgeting, accounting statement formulation, and capital risk pooling to ensure unified analysis of financial business information and reduce The risk of missing financial information and enhanced supervision. In addition, the financial and regulatory deficiencies of large and medium-sized enterprises may lead to deviations in financial information, such as costly unreasonable collection, unreasonable classification of accounting subjects, etc., which reduces the accuracy of financial information management, and clears vouchers and statements through the Financial Shared Service Center. The unified format, accounting subjects, bill management, tax adjustment and labor settlement templates, fixed asset templates, etc., have improved various financial management work, avoiding inconsistent implementation in various regions, and achieving automation of financial accounting mechanisms and integration of financial analysis. Reduce the disadvantages of work efficiency due to different professional qualities. On the other hand, improving the financial working mechanism through the shared service center can improve the utilization rate of financial information sharing, maximize the dynamic sharing of information transmission, and play the backing value of financial management in the enterprise market competition, and the financing investment of enterprises. Comprehensive monitoring of normal operations, so that enterprises can better develop their operations.

The traditional financial management mode used by large and medium-sized enterprises has not been monitored in time, and information collection is inconsistent. Many project approvals and follow-up approvals are required for project declaration and fund application, and payment delays often occur, resulting in branch companies only violating enterprises. It is stipulated that there is no contract prepayment, which limits the development speed of the enterprise to a certain extent, and the financial sharing service center implements the application mechanism that can improve the business information, and uses the information platform to timely process the capital declaration of each region, so that it can also The reasonable planning and post-budgeting of funds ensure the authenticity and timeliness of the financial data of the enterprise. In addition to business information, financial information of other companies' financial receivables, payables, bond relationships, and capital increase and decrease can also be updated in real time through the shared service center. As a core platform, timely collect and analyze various financial information of the enterprise, so as to achieve the boundary has no geographical dynamic management, which in turn enhances the sharing of financial data of enterprises, and maximizes the use value of the shared service center to provide financial information needs for enterprises.

The management talents of the financial sharing service center are divided into three types of responsibilities: operational financial personnel, operational financial personnel, and management financial personnel. They must not only possess professional accounting knowledge, financial data analysis and analysis skills, but also skillful use. Modern information technology is the integration 
and sharing details of each financial management. Because the main mechanism of the financial shared service center is "sharing" and "service", the platform will centrally link and coordinate the financial personnel of each branch to ensure the integrity and clarification of the working form and solve the independent accounting. At the same time, it is necessary to set up different reward and punishment systems and assessment criteria to ensure fair, open, fair and reasonable evaluation of individualized performance, thereby improving the professional level and efficiency of financial management personnel, and assisting enterprises in information statistics and financial accounting. The management of capital budgets, strengthen the correct understanding of big data information services, in addition to the improvement of the level of financial professional knowledge, we must strengthen the awareness of professional ethics and job responsibilities, so that each financial staff can fully control the financial information sharing service center The management system maintains the system security of the shared service center.

Financial management personnel must carefully analyze the development plan and actual income of the enterprise when conducting management activities and strategic planning. We must use the shared service center to provide accurate profitability management reports and standard budget preparation for enterprise strategic planning to ensure that enterprises are developing. Strategic planning can have accurate funding sources, revenue cost data and market information. In the investment budget and production planning, the shared service platform can be used to combine the financial analysis of other branches and the operational data adjustment strategic plan of each department to break the strategy through real-time communication. The regional barriers in the real-time link ensure the authenticity of the implementation of the plan, reduce the chaotic scenes of the plan failure caused by analysis errors or insufficient information collection, especially in the important development strategy decision-making process, pay attention to the sharing and service of property information, under the principle of confidentiality Provide the longest development guarantee for the company to develop strategic planning.

The capital investment project of large and medium-sized enterprises is another large-scale project that obtains profits in addition to the normal operation of the enterprise, and the risk of capital investment is the most control of the project. Try the financial sharing service center management to collect market information and project data comprehensively, select the most suitable investment plan from the scientific dynamic point of view, accurately grasp the best investment opportunities, and avoid the idle waste of venture capital and capital. When using the Financial Shared Service Center to make investment project decisions, the financial personnel should select the most suitable investment project according to the investment needs and investment cost of the enterprise, carefully check the feasibility of the investment project, and scientifically analyze the selected investment plan and its amount of money used in each year and the total amount of invested capital required for each year of the investment project strive for maximum control of the risk level of the investment project, and strive for the maximum investment benefit for the enterprise.

\section{Conclusion}

In summary, the introduction of the shared service center management model in the financial management of large and medium-sized enterprises in China can effectively solve the defects and shortcoming of decentralized corporate finance, and improve the overall efficiency of enterprise financial management through an integrated and centralized shared service center. Improve the analysis and collation of accounting information, so that all departments of the enterprise's human resources department, procurement and sales, business development, and logistics management are integrated, and the high-quality professional management team of the enterprise is concentrated to provide a clear capital status for the enterprise. Long-term future planning has stronger competitiveness in market competition. 


\section{References}

[1] Yang Feilong. How to establish a financial shared service system for large and medium-sized enterprises and its implementation [J]. China Business Review, 2016, (16): 51-52.

[2] Wang Huihui. Information Construction of Financial Sharing Service Center [J]. China Business Theory, 2018, (2): 128-129.

[3] Zhang Dingjin. Analysis on the Operation Effect of Management Mode of Large and Medium-sized Enterprises' Financial Shared Service Center [J]. Modern Corporate Culture, 2015, (18): 101-101.

[4] $\mathrm{Xu}$ Duolin. Construction and Implementation of Financial Sharing Center for Large and Medium-sized Recycling Resources Enterprises [J]. Renewable Resources and Circular Economy, 2016, (8): 27-30.

[5] Ren Congyan. The strategy of internal control of large and medium-sized enterprises [J]. China Foreign Investment, 2010, (9): 85-85, 88. 